\title{
Specialist Clinical Legal Education: An Australian Model
}

Susan Campbell* and Alan Ray**

Clinical legal education in Australia traditionally has been based in generalist clinics, where the client and caseload intake is limited primarily by the financial means of clients rather than by the legal subject matter of their problems. The breadth and variety of legal problems which confront clinic students provide insight into and understanding of the operation of the legal system at the grass roots and the legal issues raised rarely seem to reflect directly the law the students have learnt in the classroom.

In recent years, for both educational and political reasons, Australian Universities have begun to develop specialised clinics, serving clients with problems in a particular area of law.

This article describes the operation of Monash's specialised Family Law clinic and considers the factors which, in the Monash experience, have combined to ensure its stability and recognition, within the University and in the broader political context.

In 1996 Monash in conjunction with Springvale Legal Service (the community legal service which takes the majority of Monash clinical students) proposed the development of a series of specialised clinics ${ }^{1}$. The objective is to provide students who have completed the general clinical undergraduate subject with the opportunity to develop the skills they have learnt to a more sophisticated level and to gain a deeper understanding of the operation of the legal system through immersion in a particular area of law.

The first Monash/Springvale specialised clinic began in 1996, jointly with the South East Centre against Sexual Assault, providing legal advice and assistance to victims of sexual assault ${ }^{2}$.

The second, the Forensic Psychology and Sentencing Clinic, operated jointly with students from the Monash Department of Forensic Psychology to provide psychological assessments and the preparation of detailed sentencing material for clients charged with relatively serious criminal offences.

* Susan Campbell, Professorial Fellow in Legal Practice, Faculty of Law, Monash University, Australia.

** Alan Ray, Lecturer in Law, Faculty of Law, Monash University, Australia.
1 Evans, A. "Specialised Clinical Legal Education begins in Australia” (1996) 21(2) Alternative Law Journal 79

2 Evans, A, "Specialised Clinical Legal Education begins in Australia" (1996) 21(2) Alternative Law Journal 79 
The third, and so far the most "successful" (for reasons to be discussed below) is the Family Law Assistance Program, a clinic assisting unrepresented Family Law clients.

\section{Background}

In 1996 the newly elected conservative Federal government announced a program of reduction in legal aid funding. Community legal centres, including clinics, began to notice increasing numbers of family law litigants who had either exhausted their limited entitlement to legal aid or who had been denied aid from the outset ${ }^{3}$. The government, which has constitutional responsibility for family law, resisted growing calls for the restoration of legal aid funding but sought to institute a range of alternative measures which might be seen to solve the problem. One such measure was the discovery by the government of clinical legal education, with its use of students as "free labour" and its connection with Universities, which might be expected to contribute to the costs of programs.

In its 1998 budget the government allocated funding for new clinical legal education projects "to maximise service delivery to disadvantaged clients and co-operation with universities" ${ }^{4}$. Monash therefore applied under the new program to establish a clinic conducting self-help workshops to assist family law clients without representation either by a private practitioner or through legal $\operatorname{aid}^{5}$. The application focussed on the conduct of workshops to encourage in clients a philosophy of self-help and mutual support ${ }^{6}$.

The proposal also envisaged a website to extend advice and assistance with the completion of Family Law documents to rural and regional clients?

The project was one of four to receive funding 8 and the clinic began operation in mid-1999. Staffing consists of one fulltime solicitor/supervisor position and one full time administrative position, supported by final year Law students. Currently the clinic is fortunate to have two extremely experienced family lawyers sharing the supervisor role. The administrative position has come to be held by students from the program, whose personal experience of day to day operations and of the needs of incoming students makes them ideal administrators.

The University contributes a range of infrastructure costs.

3 For a discussion of the new legal aid arrangements and whether the increase in unrepresented litigants can be ascribed to them, see Family Law Council, Litigants in Person - A Report to the Attorney-General, August 2000 , at $1.18-1.36$, and reports referred to therein.

4 Commonwealth Attorney-General, Media Release, "Community Legal Services expanded" 3 May 1998. For a detailed discussion of the political context of the Government's decision, see Giddings, J 8 Hook, B “The Tyranny of Distance: Clinical Legal Education in 'The Bush"” (2002) International Journal of Clinical Legal Education 64.

5 Earlier in 1998 Monash had put a submission to the Legal Aid and Family Services Branch of the AttorneyGeneral's Department for funding to develop self-help kits for unrepresented family law litigants.

6 Monash and Springuale Legal Service had for some years used the workshop format to assist clients with Child Support claims.

7 See Giddings, J Eु Hook, B, "The Tyranny of Distance: Clinical Legal Education in 'The Bush"' (2002) International Journal of Clinical Legal Education 64 for a detailed discussion of the social and political significance of rural and regional clients. However, with the additional demand on resources resulting from the Family Court Support Program the web-site proposal was abandoned.

8 Of the three other funded projects, two were specialised clinics: a Child Support/Family Law clinic at Griffith University, Queensland and an Employment Law clinic at University of New South Wales/Kingsford Legal Centre. The fourth was the establishment of a new generalist clinic at Murdoch University, Western Australia. 


\section{The Family Law Assistance Program (FLAP)}

The new clinic operates from Monash-Oakleigh Legal Service (MOLS), a community legal centre conducted by the University on campus ${ }^{9}$. While initially the concept of workshops, with up to four clients participating in each, was followed, it quickly became clear that clients' individual needs (including language needs) are so diverse, and their level of anxiety generally so high that workshops were simply not effective and were liable to frustrate clients rather than to empower them. The clinic therefore reverted to the individual interview model followed in the generalist clinics.

The educational model is also the same as that in Monash generalist clinics: a student interviews the client without the supervisor present, obtains instructions, then discusses the issues privately with the supervisor in his/her office. The student then returns to the client

with initial advice. If, as is often the case, the client needs documents to be prepared, the student may sit down with the client at a computer (which is equipped with the full range of Family Court document templates) and assist the client to complete the relevant documents. In cases where the client does not have the language or literacy skills to complete documents even with assistance, the student will complete them. In all cases the supervisor checks the final documents before the client signs and/or swears them.

The program does not act as solicitor on the record for clients; they continue to conduct their matter in their own name. Thus, once documents have been completed, the client is given detailed advice on filing and service and on the "litigation pathway" to be followed. Another appointment will be fixed at the appropriate stage of that pathway so that the client can obtain advice on the next steps, discuss any offer of settlement or prepare an appearance.

\section{Statistics}

FLAP sees on average 8 clients per session with 4 sessions per week. Allowing for University holidays and an occasional closure to allow staff to catch up on paperwork and Government reporting obligations, this means that the program sees approximately 1550 clients per year.

\section{Evaluation}

No formal evaluation of FLAP has been conducted. Client demand and referrals from the Court indicate that stakeholders regard it as providing an invaluable service.

9 The decision was made to establish the new clinic at Monash-Oakleigh Legal Service, rather than at Springvale Legal Service, for reasons of space. A small amount of project funding was used to expand MOLS premises to add a dedicated workroom and a staff office for the new program. 


\section{The Family Court Support Program (FCSP)}

Shortly after its inception, FLAP became involved in an unexpected but significant extension of its work.

The local Registry of the Family Court ${ }^{10}$ has the highest percentage of unrepresented litigants of any registry in Australia ${ }^{11}$. To discuss ways of addressing the inherent inequalities in this situation and assisting the Court to operate efficiently, Registry staff met with several community agencies, including FLAP, and the outcome was the Family Court Support Program (FCSP). This adopts a team-based approach to provide a range of services in the one location.

The court staff ensure, as far as the listing system will permit, that all matters involving unrepresented litigants are listed on a Monday. The FLAP solicitor attends with a number of students, as does a duty solicitor from Victoria Legal Aid and staff of the Court Network (a volunteer group which provides non-legal advice and support to unrepresented litigants). (In the early days of the FCSP the local community-based mediation centre also attended, with the intention that mediations could be conducted "on the spot". However this proved to be an inefficient use of limited mediation staff resources and the centre's participation in the program ceased.)

As each litigant arrives at court, they are asked by a court official if they need legal advice. If so, the litigant is interviewed by a student and, after consultation with the supervisor, provided with advice and, where needed, assistance with the preparation of documents.

Where the opposing party is also at court, the student will discuss possible resolution of the issues with the client, again after consultation with the supervisor, and with the client's instructions negotiate with the opposing party or their representative. Often the opposing party is also unrepresented and she/he can obtain advice from the Victoria Legal Aid duty solicitor, thus avoiding the situation which would otherwise occur of "first come/first served", where the party who happens to arrive at court first can effectively corner the provision of legal advice and prevent the opposing party from obtaining access to such advice.

If a settlement cannot be reached, the client goes away equipped with a more detailed understanding of the procedure to follow and with the reassurance that they can seek the advice of the Program on their next day in court.

If settlement between the parties can be agreed upon, the student will draft consent orders and appear before the relevant judicial officer to obtain approval of such orders. The fact that the matter can be finalised on the day is one of the reasons why the Program is valued so highly by both clients and the court; if clients were forced either to appear for themselves or to return to court on another occasion with representation, the sense of mutual achievement in reaching an agreement would be diminished. Indeed many parties might use the time spent waiting for the next court date to change their mind about settlement. However it might be thought highly unusual that students actually appear in court on behalf of clients.

10 at Dandenong in the outer suburbs of Melbourne. Its catchment area includes higher than average levels of unemployment and language disadvantage
$1140 \%$ across the three main categories of applications filed - Family Court of Australia, Dandenong Registry, internal working paper, 1999. 


\section{Students appearing in court}

In all Australian jurisdictions, only admitted practitioners have the right to represent a litigant. But every court has an inherent discretion to control its own proceedings and, as part of that discretion, to permit unqualified persons to appear on behalf of a litigant ${ }^{12}$. In the higher courts such leave is rarely granted ${ }^{13}$.

However for some years Monash has operated a "Student Appearance Program" as part of its generalist clinics. This program arose out of the increasing numbers of clients attending the clinics who on any view needed legal representation in minor criminal or family law matters but who did not qualify for legal aid to pay for such representation. Monash therefore put a proposal, initially to the Magistrates Court (the lowest court in the hierarchy in Victoria) and subsequently to the Family Court, that clinic students should be permitted to represent their clients in certain categories of matters before these courts. It is indicative of the concern felt by both courts about the numbers of unrepresented litigants that members of both courts generally welcomed the proposal.

As a result, in the ten years since this program began, Monash students have represented more than 100 clients per year, largely in pleas of guilty in summary criminal matters and in divorces and uncontested family law applications, particularly where the client is of non-English-speaking background.

When the Family Court Support Program was established, therefore, there was simply no debate about the role of students in representing clients before the Family Court.

\section{Statistics}

The FCSP sees on average 20 clients per day for approximately 49 weeks per year.

\section{Evaluation}

A preliminary evaluation of the FCSP was conducted jointly by the Court and Monash after the first 8 months of operation ${ }^{14}$.

Broadly, the objectives of the project were to evaluate: whether matters in which litigants were assisted by the FCSP were resolved in a more timely and cost effective way than those not involving FCSP assistance; whether clients were generally satisfied with the services provided by the FCSP; and whether the judicial officers at the registry were likewise generally satisfied.

The quantitative sections of the research, designed to assess whether the FCSP contributed to the "efficiency" of the Court process, were inconclusive. While FCSP clients made fewer appearances in court and took a shorter time to conclude their matter from filing to resolution, the difference between FCSP clients and others was not statistically significant.

However the results of the qualitative research, based on questionnaires completed by clients and interviews with judicial officers, showed overwhelming support by both groups.

12 O’Toole v Scott [1965] AC 939 (Privy Council)

13 Damjanovic v Maley [2002] NSWCA 230

14 Campbell, Susan 8 Shaw, Sally, "An Evaluation of the
Family Court Support Program at the Dandenong Registry of the Family Court of Australia" Report to the Attorney-General of Australia, April 2001, unpublished. 
Clients commented both on the fact of receiving advice in terms they could understand and on the personal support and confidence they obtained from the FCSP. Typical comments were:

"I found the advice extremely helpful, easy to understand and correct."

"I received step by step help with the documents I had to supply to the court. The legal terms were put simply for me to understand."

"I was feeling very intimidated by having to represent myself. The [FCSP] staff made me feel good about myself."

"This has given me confidence that paperwork and procedures can be successfully completed by myself, this takes a lot of stress and the feelings of hopelessness out of what for me has been an ongoing dilemma."15

As to the opinion of judicial officers, most commented on their perceptions of the increased confidence of litigants, the improvement in quality of documents presented and, regardless of the statistical results, a higher rate of settlement. Several stated that the FCSP should be extended to more days of the week and that similar programs should be established at other registries.

Despite the inconclusive results of the quantitative research, the Court continues to believe that the FCSP is of value to it and other registries around Australia have discussed ways of establishing their own version of the program. It is hoped to conduct a more substantial evaluation project in the future.

\section{The Student Experience}

The students in the program are drawn from three sources:

a. Students taking the final year subject Advanced Professional Practice ${ }^{16}$ who have completed the generalist clinical subject are with the program for the whole semester. Their workload is two sessions per fortnight - the first week is a session at the Family Court and the second week a half-day at MOLS. There is usually follow-up work required on their ongoing files.

b. Students taking one of two Family Law electives as an optional subject in the undergraduate degree may elect to participate in FLAP for five half-day sessions. This will represent $40 \%$ of their final assessment for the subject. Four of these sessions are at MOLS and one is as an observer at the Dandenong Family Court. Students who have completed a placement as part of one Family Law elective and wish to take another in the second subject are permitted to do so but they are required to spend two days at Court, thus building on their experience in the first placement.

c. Volunteers, who are usually ex-students of FLAP, offer their services on an ad hoc basis. Occasionally law students from other universities, and even practitioners from overseas seeking to gain experience of the Australian legal system, volunteer.

15 Quotations are taken from the Report.

16 Advanced Professional Practice has been created as a subject 'home' for all Monash specialized clinics. It is formally a one semester elective subject in the undergraduate degree. 
At the start of the semester students receive an orientation tutorial which provides them with material on interviewing and drafting skills, annotated instruction sheets, glossary with index to precedents, overview of library resources and a general introduction to office procedures. More experienced students are paired with a junior student for their first interview to provide a mentoring role.

\section{Assessment}

For Advanced Professional Practice students who have had the conduct of some ongoing files, there is a "file review" at regular intervals, with the final assessment based on their performance over the semester $(80 \%)$ and a written assignment $(20 \%)$. This assignment is to discuss in detail two issues or problems encountered in the program with appropriate reference to legislation and case law and a reflection on the perceived need for changes to law and practice.

Students participating in FLAP as part of a Family Law subject are assessed on the quality of their participation in the program $(25 \%)$ and a reflective piece on the program $(15 \%)$. Many students do elect to take a second Family Law subject and to do a second placement and they comment on the fact that the skills learnt in the first placement are reinforced in the second, partly because they take a mentoring role with new students.

\section{What do the students learn?}

Clinical legal education which is integrated into the curriculum engenders enthusiasm for legal practice in the students because they can better appreciate the relevance of theoretical lecture material. In addition, it teaches them the portable skills of interviewing, drafting, negotiating and elementary advocacy in an environment in which they can feel comfortable and able to learn. Students are challenged to consider whether the law in practice differs from the law in theory and whether legislation or practice should be changed to ensure a more "just" result for all members of society.

Although the educational aims of the FLAP/FCSP program are the same as for any other form of clinical legal education, the more specific aims are slightly different for each category of student.

The Advanced Professional Practice students have learnt and applied fundamental interviewing skills in the generalist clinic and they are expected to develop these further in their FLAP experience. In the generalist clinic each student would almost certainly have conducted interviews in Family Law matters but they will not have had the depth of experience involved in providing detailed advice in contested matters, as the generalist clinics only handle uncontested/consent matters.

Furthermore while the unending variety of problems seen at the generalist clinics teaches students to be able to identify and analyse issues across almost every conceivable area of law, by definition they are rarely able to develop a depth of knowledge in any area.

Those students who took part in advocacy in the generalist clinic had the luxury of being able to prepare the matter thoroughly and were not called upon to appear in the pressure of the Family Court at relatively short notice.

For the Family Law students, it is clear from their written work that their learning extends across a gratifying range of understandings. 


\section{Integration of theory and practice}

"It was at [FLAP] that family law leapt from the pages of my lecture notes to become a much needed legal recourse to real people in problematic situations."

"FLAP quickly demonstrated that the study and practice of Family Law can involve vastly different types of knowledge. On my first morning I learnt that a divorce costs $\$ 575$, that nearly every application will require at least 3 forms and that a Family Court will reproduce a copy of previous orders for no charge."

"The reality of cases required my own identification of the important facts, drawing a sharp contrast with the textbook cases where the facts are apparent."

\section{Professional skills}

"Interviewing clients has refined my ability to listen and ask questions that elicit the relevant information. A client may be distressed or simply as a non-legal professional unaware of the information the court is interested in, such that they may pour out the whole story including a lot of information that is irrelevant or contentious. I realized that it was my responsibility to direct their thoughts and answers towards getting the outcome they were after."

"I was interested in whether, and how, I could achieve a balance between listening to the client in a sympathetic way and getting down the facts and finishing the interview on time."

"For much of the day I attempted to negotiate with the mother's barrister...Although this was daunting I gradually become more comfortable and confident. I was initially concerned that my knowledge and experience deficit would mean that the barrister could effectively tell me anything. In general he was understanding of my limited knowledge but towards the end of the day he began to exaggerate his arguments... [eventually] I made a brief appearance, confirming the content of the [interim] orders and the return date. The opportunity to sit at the Bar Table and address the Court gave me great confidence. The barrister then loudly commented that I had been very professional and a pleasure to work with"

\section{Thinking like a lawyer}

"On a conceptual level, I found that there is fundamental difference between the way in which a law student and a client think about the law. Law students understand that the law provides a series of very limited avenues to obtain specific outcomes. My clients just wanted their problems solved....... I also found that there is an equally fundamental difference in the way that a student and a solicitor survey a client. It took several weeks for me to stop focusing exclusively on obtaining valuable information from the interview and be able to step back and critically assess the prospects of my client's application." 


\section{The requirements of professionalism}

"The second interview I conducted was related to a dispute over contact of a child. We were acting for the husband who the wife was alleging had sexually abused the daughter.....Looking back I realised that I wasn't as compassionate or [attentive] towards this client as I should have been. The main reason I want to practice Family Law is because I want to protect children and when you have allegations of abuse of some sort you start to wonder who it is you are representing. It wasn't until I was in the room with him and interviewing him that I realized that practising law requires such objectivity and I wasn't sure in this situation if I could do that. But as the interview progressed I sort of switched off my emotions and listened to what he had to say. ...I found that interview quite hard. I was judging this client because of allegations and our criminal justice system presumes innocence until proven otherwise, yet there I was looking at this man and feeling quite scared and awful in myself for helping him to get access to his child. Yet he could very well be innocent of the allegations. This was the hardest interview I took at FLAP...for the first time I realized that whatever area you wish to practice in, you can't choose your clients.."

"I also became aware of how much trust a client has in legal professionals and the privilege a legal professional has in receiving such personal information from clients. At the briefing before the placement we were reminded of our duty of confidentiality."

"In my interaction with this client, I thought I had been friendly and empathetic, making the occasional joke to relax the client and make his Court experience less intimidating. However, [the supervisor] felt that the client had been 'too friendly' and had enjoyed my company 'too much'. While he emphasized that this was not my fault, he warned me to be careful in my future career. This came as a shock as I had not felt uncomfortable. [My supervisor] pointed out that particularly in Family Law, the lawyer is often the 'knight in shining armour', the person with stability and firm answers when all else in the client's life is deteriorating. Whilst a surprising assessment of the client, the comments were a confronting but important lesson to learn at this early stage."

\section{The failings of the legal system}

"The advanced placement reiterated the inadequacy of a legal system that is stretched to the point where undergraduate students are the best source of legal advice on offer to many people."

\section{And finally}

"From the first day of placement til the last day at the Dandenong Registry of the Family Court it's been hectic, interesting, educational and strangely fun. It's probably not the best thing to admit enjoying yourself considering that most people who come to [FLAP] are often fighting a battle where there will never be a winner or loser and what they're fighting for often involves their own children."

As all clinical teachers know, it is the intensity of the students' learning experience which makes being a teacher so rewarding. 


\section{What Makes a Successful Clinic?}

The Monash experience with specialised clinics suggests that there are three factors (or 'inputs') necessary to ensure that a new clinic functions effectively, provides appropriate experience for students, meets client demands and operates for a significant period. These factors are:

- client demand;

- student demand; and

- funding.

These may seem so obvious as to be not worth mentioning but when planning a new generalist clinic, the first two factors can usually be taken for granted. Clients will come from near and far to obtain advice and students will enthusiastically support any opportunity to obtain practical experience.

With a specialised clinic, the very fact that it will be handling cases only in a specified area raises more complex issues. With the Monash Forensic Psychology and Sentencing clinic, the issue was client numbers. Because the clinic was seeking clients charged with relatively serious criminal offences, referrals from the Monash generalist clinics could not supply sufficient clients. Victoria Legal Aid, which funds the great majority of criminal trials, was willing to refer clients for psychological assessment by the clinic, but would not refer any part of the preparatory legal work. That left the Law students with insufficient work to retain their interest (or to justify the award of academic credit).

With the Sexual Assault clinic, there is no lack of clients (unfortunately) because they are referred by the Centre against Sexual Assault. The issue here is student demand. Of those students who have completed the generalist undergraduate subject, very few choose to take a subject specializing in legal issues relating to sexual assault. (It has been suggested that they may be wary of the reaction from employers.) Thus this clinic has enough clients but very few students and in some semesters has to rely on students staying on as volunteers.

Funding the cost of supervising staff, premises etc, is an issue never taken for granted. But it is itself usually dependent upon a satisfactory level of client demand, for government funding, or student demand, for University funding.

It is for these reasons that the Family Law clinic has been the most "successful" of the three Monash specialised clinics. As indicated earlier, the client demand is inexhaustible. Initial student demand, when the clinic was taking only those students who had completed the generalist clinical subject, was problematic; student may have felt that they had experienced sufficient family law already. The breakthrough came when it was decided to open the clinic to students taking the Family Law academic subjects. These students by definition have made the decision to take a Family Law subject and it may be that the four week placement is more attractive than the concept of working at the clinic for the whole semester. In any case these students are very keen to gain practical experience and each semester between 50 and 70 students elect to enrol in the placement. This therefore guarantees more than enough students to meet the client demand.

The third factor, funding, also differentiates the Family Law clinic from the others. With the grant of government funding, staff salaries are provided for and the University's contribution is relatively small in proportion to the popularity of the clinic with students and its significance as a form of University community service. 


\section{CONCLUSION}

There is one remaining issue which most clinicians will be conscious of and which seems particularly pointed in the context of specialised clinics. Should we be filling the gap in public legal aid and thereby letting governments off the hook?

There is no easy answer to this question. At Monash our decision usually is the pragmatic one it is extremely hard to turn clients away when their problems are real and pressing and we have the capacity to help them.

But it is slightly easier to live with this compromise in the context of the Monash philosophy that the educational needs and the legal needs of clients are equally important. As Adrian Evans has pointed out ${ }^{17}$, 'students are encouraged to see that their own education and the empowerment of their clients are mutually dependent. The ethos here is that clients who acquire legal power from interactions with students legitimise the learning process for those students. The element of potential exploitation by students of their clients in the interests of the future income-earning potential of the students is to this extent diminished or eliminated.'

\section{Bibliography}

1. Specialised Clinical Legal Education begins in Australia (1996) 21(2) Alternative Law Journal 79, Evans, A

2. Litigants in Person - A Report to the Attorney-General (August 2000), Family Law Council

3. Community Legal Services expanded (3 May 1998) Media Release, Commonwealth Attorney-General

4. The Tyranny of Distance: Clinical Legal Education in 'The Bush' (2002) International Journal of Clinical Legal Education 64, Giddings, J \& Hook, B

5. Internal working paper (1999), Family Court of Australia (Dandenong Registry)

6. O’Toole v Scott [1965] AC 939 (Privy Council)

7. Damjanovic v Maley [2002] NSWCA 230

8. An Evaluation of the Family Court Support Program at the Dandenong Registry of the Family Court of Australia (April 2001), Report to the Attorney-General of Australia (unpublished), Campbell, Susan \& Shaw, Sally

9. Adrian Evans: an Australian perspective, Clinical Legal Education - Active Learning in your Law School, Brayne, Duncan \& Grimes

17 Adrian Evans: an Australian perspective in Brayne, Duncan $\mathcal{E}$ Grimes, Clinical Legal Education - Active Learning in your Law School pp.269-270. 
